\title{
JOSÉ DE GOIS E MORAIS: O PAULISTA QUE QUASE COMPROU SÃO PAULO.
}

\author{
SUELY ROBLES REIS DE QUEIROZ \\ Do Departamento de História da Faculdade de Filo- \\ sofia, Letras e Ciências Humanas da Universidade de \\ São Paulo.
}

Em começos do século XVIII, mais precisamente em 1708, um paulista de nobre linhagem propunha ao donatário da Capitania de Santo Amaro a compra das 50 léguas de terra de que êste era possuidor. Tal aquisição tornaria José de Góis e Morais, assim se chamava o comprador em potencial, dono e senhor da região onde nascera.

A Capitania de Santo Amaro, doada a Pero Lopes de Souza em 1532, compunha-se de duas porções de terra: uma de 10 léguas, mais setentrional, situada nas imediações dos rios São Vicente e ICurubacê ou Juquiriquerê. A outra porção, de 40 léguas, principiava ao sul de Cananéia e confinava com a Capitania de São Vicente, doada a Martim Afonso de Souza e que continha 100 léguas de extensão, também separadas em duas porções, no meio das quais ficavam como que encravadas as 10 léguas de Pero Lopes (1).

Essas doações de terras não contínuas deram origem, posteriormente, a confusões quanto à delimitação das donatarias.

A princípio, ninguém duvidou de que as capitanias dos dois irmãos se dividiam pelo braço do rio São Vicente depois conhecido como Barra da Bertioga. Com o tempo porém, divergiram os pareceres dos moradores a respeito do rio por onde se devia fazer a partilha, assentando alguns que seria pela Barra da Bertioga e outros, que a Capitania de São Vicente deveria principiar na Barra de Santos (2).

(1). - Cf. Frei Gaspar da Madre de Deus, Memórias para a história da. Capitania de São Vicente, São Paulo, 1954, pág. 151.

(2). - Segundo Frei Gaspar (ob. cit., "pág. 166), foi o sèsmeiro Gonçalo Afonso que semeou a dúvida, procurando em 1542, induzir D. Isabel de Gamboa, já então viúva de Pero Lopes de Souza, a considerar como limite das Capitanias a Barra de Santos, o que incluiria a ilha de Santo Amaro em seu quinhão. Como possuia terras nas vizinhanças, pode ser que Gonçalo Afonso tivesse o intuito de vir a ser "gove: nador do País onde morava", o que foi baldado, pois D. Isabel conferiu a outro a distinção. 
A Carta de' Doação feita a Martim Afonso esclarecia a questão pois determinava que o padrão de posse fôsse erguido

$$
\text { "no rio de São Vicente, braço da banda do Norte" , }
$$

isto é, na Barra da Bertioga, mas dona Ana Pimentel, espôsa de Martim Afonso, descuidou-se em mandar uma cópia autêntica da Carta para São Vicente, favorecendo assim o engano.

De acôrdo com a Carta de Doação, começando a capitania de São Vicente na Barra da Bertioga, nela se incluiria a ilha que passou a ser conhecida como Santo Amaro (3).

Povoadas as terras entre os rios de Santos e Bertioga e que correspondiam à capitania de São Vicente, passaram os moradores a se introduzir nas 10 léguas de Pero Lopes, originando novas confusões quanto aos verdadeiros possuidores das donatarias:

"nunca se emendou o êrro de falar nas 10 léguas como pertencentes à Capitania de São Vicente, sendo elas de Santo Amaro" (4).

Esse engano continuou até ao tempo em que às duas capitanias, de São Vicente e Santo Amaro, deu-se o nome de Capitania de São Paulo (5).

Quanto à̀s quarenta léguas ao sul de Cananéia, povoadas mais tarde por moradores de Cananéia, ficaram sob a jurisdição desta última, em razão de nelas não haver até então nenhuma povoação com Câmara.

Novamente os habitantes dessas terras supuseram errôneamente que elas pertenciam à Capitania de São Vicente.

Por aî se vê que os limites territoriais das duas ICapitanias eram bastante controversos, dando margem a contínuas contestações.

A posse de São Vicente e Santo Amaro foi ainda durante o século XVII, motivo de acirrada disputa .

Dona Isabel de Lima de Souza e Miranda, descendente de Pero Lopes de Sousa e última representante de uma geração que com ela se extinguia, determinou que a sucessão em suas donatarias competiria a Lopo de Souza, seu primo e donatário de São Vicente.

(3). - Essa ilha era inicialmente a chamada Guaibe. Por volta de 1544 alguns devotos edificaram nela uma capela dedicada a Santo Amaro, denominação que depois se estendeu não só à ilha, mas também às 50 léguas de Pero Lopes.

(4). - Frei Gaspar, ob. cit., pág. 182.

(5). - Em 1709 a capitania de São Vicente, até então adjudicada à do Rio de Janeiro, desliga-se desta última e passa a englobar o território das minas com o título de Capitania de São Paulo e Minas do Ouro. 
Com isso não se conformou o conde de Monsanto, outro neto de Martim Afonso que, opondo-se à sucessão, moveu demanda contra o primo. Como Lopo de Souza morresse em 1610, a contenda continuou contra sua irmã e herdeira, a Condessa de Vimieiro. Arrastou-se por muitos anos, compreendendo momentos em que o ramo Monsanto procurou apossar-se também de vilas pertencentes à Capitania de São Vicente (6) .

Durante as várias décadas em que durou a contenda Monsanto-Vimieiro, nenhum dêles governou as Capitanias, sendo os capitães, ouvidøres e oficiais de justiça, nomeados pelo Rei ou pe'o governador geral, na falta de Provisão Régia. habitantes e

As disputas territoriais e contestações de posse confundiam os "apesar porém de haver nas terras chamadas de São Vicente
duas capitanias e dois donatários, na realidade quase que se ima-
ginavam uma só" (7).

Dessa forma, a região que, tomando o nome da vila humilde do planalto, passaria a ser conhecida por São Paulo e cuja porção principal compreendia a capitania de São Vicente, ainda se ressentia, no início do século XVIII, dos entraves decorrentes das divergências entre os descendentes de Martim Afonso de Souza.

Escassamente povoada e com parcas perspectivas econômicas, em nada sugeria o grande destino para o qual nascera.

Fraca agricultura, só de subsistência. Comércio acanhado, população a desfalcar-se contìnuamente em grandes levas, por causa da miragem do ouro que a todos empolgava e que já começara sua atraente e efêmera trajetória.

O que era válido para a Capitania, mais ainda o era para a pequenina vila que se originara do colégio dos jesuítas, iniciando-se

"a existência setecentista de São Paulo em período de estranha agitação, numa fase do mais profundo abalo e perturbação das condições de vida, em época de formidável depressão, decorrente do êxodo enorme de uma população já de si escassa" (8).

As espantosas notícias das mais recentes descobertas nos sertões dos Cataguazes, à margem dos rios auríferos, misturando lenda e rea-

(6). - Maiores detalhes sôbie essa contenda são encontrados em Frei Gaspar, ob. cit. e Machado de Oliveira, Quadro Histórico da Provincia de São Paulo.

(7). - Varnhagen, História Geral do Brasil, 5.a edição, vol. II, pág. 17.

(8). - Taunay (A. E.), História da vila de São Paulo no século XVIII: (1701-1711), in "Anais do Museu Paulista", tomo VI, São Paulo, 1933, pág. 3. 
lidade, conturbavam e fascinavam o país. E sobretudo a terra dos descobridores.

Surgiam os primeiros resultados da exploração da grandeza das lavras, desvairando as mais sólidas cabeças, que para as minas se iam, deixando o solo natal ràpidamente despovoado, a vegetar na pobreza.

Vivia então em São Paulo opulento cidadão que, rápida e progressivamente, vivia a atuar no cenário político e administrativo da pequena vila: José de Góis e Morais, descendente de uma das mais nobres famílias da Capitania, nascera em São Paulo.

"onde serviu os cargos da sua república" (9).

Era o primogênito do ilustre Pedro Taques de Almeida, o terceiro dêsse nome, que além de capitão-mór e governador da Capitania por patente régia, no período de 1684 a 1687, ali desempenhou numerosos outros cargos (10).

"O prestígio dêste paulista demonstra-se no fato de haver representado ao govề: no da Metrópole contra o procedimento do ouvidor-geral João Saraiva de Carvalho em 1708 e ser logo atendido com a demissão dada ao mesmo em abril de 1709" (11).

Sentindo-se velho fez ver a El-Rei a impossibilidade de continuar a exercer a administração geral das aldeias do real padroado, para o que, dando-he o monarca honrosa prova de confiança, sugere-lhe que êle próprio nomeie pessoa capaz de substituí-lo. Ainda assim,

"não se aproveitou da liberdade de eleger pessoa ou pessoas para o pesado serviço de administrador das aldeias do real padroado, porque soube até cortar pelo interêsse próprio, deixando de nomear o seu filho José de Góis e Morais, que já neste tempo tinha dado reconhecidas mostras de seu zêlo em serviço do seu monarca" (12).

(9). - Leme, Pedro Taques de Almeida Pais, Nobiliarquia Paulistana Histórica e Genealógica, tomo I, São Paulo, 1954, pág. 151.

(10). - Como já foi mencionado, duiante o periodo mais agudo da contenda Monsanto-Vimieiro, nenhuma das partes exerceu o direito de governança, sendo as autoridades nomeadas pelo governador geral ou pelo rei. Daí a indicação real de Pedro Taques para capitão-mor, e governador. Foi ainda comandante da fortaleza de Itapema em Santos; provedor e contador da Fazenda Real da Capitania de São Paulo; juiz da Alfândega e Vedor da gente de guerra da Praça de Santos; alcaide-mor e administrador das aldeias do real padroado. Cf. Azevedo Marques (Manoel Eufrásio de), Apontamentos Históricos, Geográficos, Biográficos, Estatísticos e Noticiosos da Província de São Paulo, tomo II, São Paulo, 1954, pág. 161.

(11). - Azevedo Marques, ob. cit., II, pág. 161.

(12). - Taunay, ob. cit., (1701-1711), págs. 194-195. 
Tal a atuação de Pedro Taques de Almeida. O filho herdou-lhe e perpetuou-lhe o prestígio.

Parece certo que o fortalecimento de sua fortuna se deve à sua integração no grande movimento minerador, do qual já participavam outros eminentes cidadãos da despovoada São Paulo. Nas minas estava Domingos da Silva Bueno, mestre de campo do terço de auxiliares, a primeira autoridade militar paulistana. Nas minas vivia Domingos Dias da Sìva, juiz ordinário, opulento fazendeiro em Ajubá (13) .

Embora herdeiro dos haveres paternos, foi nas Minas Gerais, onde residiu por alguns anos que José de Góis amealhou o grosso de sua fortuna:
"passando a viver dos interêsses que convidavam as grandezas do ouro que extraiam os escravos nas Minas Gerais, nelas se fêz tão opulento em cabedais que, recolhido à Pátria, não teve no seu tempo quem o igualasse no tratamento" (i4).

Os cronistas geralmente não precisam a época em que teria vivido na região mineira, mas os documentos que registram os pedidos de sesmarias, assinalam o fato de ter êle,

$$
\text { "por estar de assento nas Minas Gerais dos Cataguaz", }
$$

requerido no ano de 1705 , sesmaria com três léguas de comprido e uma de largo, começando do

$$
\begin{aligned}
& \text { "pôrto do Rio Grande, compreendendo o sertão para, as Car- } \\
& \text { rancas e para o Rio das Mortes" (15). }
\end{aligned}
$$

Por outro lado tendo sido nomeado capitão-mór governador da Capitania de São Paulo em 1704, não exerceu o cargo por estar residindo nas Minas.

Foi um dos muitos que fizeram fortuna nas minas, lavrando ouro e dedicando-se ao comércio com os que extraiam o cobiçado metal precioso. Nas inúmeras sesmarias que solicitou, pretendia terras para a criação de gado especialmente (16).

Dessa forma, quando surge a ocasião do curioso episódio da compra da Capitania, José de Góis já teria certamente adquirido a opulência com que se fez notável.

(13). - Idem, ibidem, págs. 3-4.

(14). - Pedro Taques, ob. cit., I, pág. 152.

(15). - Sesmarias, vol. II, São Paulo, 1921, pág. 55.

(16). - Sesmarias, II, pág. 479; III, págs. 45, 46, 49, 97 e segs.; vol. VI, págs. $72,91,297$ e segs. 
O que o levaria a propor negócio de tal monta? Seria o espírito de homem público - querer ter predomínio, condições mais propícias para melhor zelar pela cousa pública? Ou a visão do homem de negócios, que antevia na transação vantagens futuras?

Diz Pedro Taques que a bem advertida idéia de José de Góis teria sido

$$
\text { "para o firme estabelecimento de sua casa" (17), }
$$

mas a vaidade bem humana de querer aumentar o seu prestígio foi o que norteou a idéia da compra. O Alvará que expõe a transação é bem claro: embora as terras pouco rendessem, queria-as José de Góis

\footnotetext{
"em razão da honra que adquiria de ficar Donatário de huma Capitania de tão vasta jurisdição" (18).
}

Assim, em 1708 (19), depois de comunicar seu intento ao pai, a quem, em conformidade com os costumes da época, sempre professou profunda obediência e respeito, propôs a compra das 50 léguas de terra da Capitania que constituía o quinhão de Pero Lopes de Souza ao então donatário, D. Luís Álvares de Tayde Castro Noronha e Souza, marquês de Cascaes (20).

Este acedeu, pois por intermédio dos procuradores de José de Góis em Lisboa, se ajustou a venda por 40 mil cruzados e mais 4 mil de luvas das ditas 50 léguas

$$
\begin{aligned}
& \text { "com tôdas as vilas que se achavám fundadas desde o tempo } \\
& \text { do primeiro donatário". }
\end{aligned}
$$

As transações eram demoradas naquela época de longas distâncias e lentos transportes. Assim, em 1710, na primeira frota do Rio de Janeiro, vieram os avisos e no regresso da mesma frota foi enviado $\supset$ dinheiro que consumaria o negócio (21).

O acôrdo entretanto, não se efetivaria:

"houve quem ponderasse a El-Rei $\mathrm{D}$. João $\mathrm{V}$ a utilidade que se seguia à sua Real Corôa ficarem a ela incorporadas as 50 léguas que o marquês vendia a José de Góes" (22).

(17). - Pedro Taques, $a b$. cit., I, pág. 152.

(18). - O alvará de compra se encontra transcrito em Frei Gaspar, ob. cit.

(19). - Essa data é mencionada por Azevedo Marques, ob. cit., II, pág. 58.

(20). - Pedro Taques refere-se à compra como se se tratasse das cem léguas de Martim Afonso, quando no entanto, p:opunha-se a transação com o quinhão de Pero Lopes.

(21). - Cf. Pedro Taques, ob. cit., I, pág. 152.
(22). - Idem. 
A Corôa ofereceu ao donatário os 44 mil cruzados em aprêço (23), celebrando-se então a escritura com o procurador da Corôa, a 19 de setembro de 1711 (24).

Esse ajuste iria repercutir na administração da Capitania, que até ali estivera sujeita aos conflitos que ocorriam entre os herdeiros dos primeiros donatários

"daí avante a autoridade tôda inteira achou-se concentrada na pessoa do governador da Capitania, as incertezas e hesitaçōes deixaram de aparecer na gerência da administração pública e esta começou a seguir uma marcha regular" (25).

Malogrado o seu intento, empregou José de Góis o capital que havia remetido a Lisboa, na compra de fazendas que seriam depois distribuídas no Rio de Janeiro. A má sorte contudo perseguiu-o, pois embarcada a mercadoria, o navio que a trazia foi saqueado pelo francês Pexelingue (26) .

Grave golpe na fortuna do paulista, mas não o suficiente para abalar-lhe a estabilidade econômica. Já nessa época, segundo Pedro Taques, seria a sua,

$$
\text { "uma das maiores casas do Brasil". }
$$

Teria o linhagista exagerado, conduzido pelos laços de parentesco? (27). Poder-se-ia pensar na riqueza de José de Góis nos mesmos têrmos em que eram lembradas as fortunas dos senhores de engenho do Nordeste na melhor época da produção açucareira?

'E' provável que em relação àquêle tempo em que viveu, fôsse realmente uma das maiores, pois os engenhos nordestinos de então, estavam desbaratados.

Parece certo que a perda não o abalou. Dizem os genealogistas como Pedro Taques que no seu tempo não encontrava parceiro em tratamento,

"porque de cavalos da melhor fama e bondade tinha muitos e todos bons em atual cavalharice, e tão briosos que nem para beber água saíam para fora sem antolhos e cabeções" (28).

(23). - Azevedo Marques e Pedro Taques falam em 45 mil cruzados e Machado de Oliveira (Quadro Histórico da Província de São Paulo, São Paulo, 1897, pág. 128) em 40 mil. Na verdade, a Corôa dispendeu 44 mil cruzados (V. Alvará).

(24). - V. Alvará em Frei Gaspar, ob. cit.

(25). - Machado de Oliveira, ob. cit., pág. 128.

(26). - Pedro Taques, ob. cit., pág. 153.

(27). - Prdro Taques era sobrinho de José de Góes. Sua mãe, Leonor de Siqueira Paes, era filha de Pedro Taques de Almeida.

(28). - Pedro Taques, ob. cit., I, pág. 152. 
Em sua casa, ricos e excelentes móveis, além de grande copa de prata (29) e

"muitos mulatos escravos e tão claros na côr que competiam com os brancos neste acidente e todos bem vestidos da libré da casa o serviam e acompanhavam de pé e de cavalo" (30).

A vultosa perda que representou o roubo do pirata francês não o impediu de continuar com os negócios a que sempre estivera afeito:

"passou a iundamentar o patrimônio de sua casa em férteis fazendas de gados vacuns e manadas de éguas nos Campos Gerais chamados de Coritiva para se utilizar dos seus grandes rendimentos na extração das boiadas" (31).

Dessa forma, tornou-se senhor das fazendas conhecidas como São João, São Car'os e São Bento.

E' a partir da projetada compra da Capitania que os textos deixam entrever-lhe uma atividade política mais acentuada .

A impressão que se tem é de que até o fim do primeiro decênio do século XVIII, José de Góis ter-se-ia preocupado em organizar a vida particular, fortalecendo a sua situação econômico-financeira.

Por essa época casou-se (32). Segundo Pedro Taques, a 21 de outubro de 1714, com dona Ana Ribeiro Leite, filha de sua prima co-irmã, dona Maria de Lara Leite (33), tendo necessitado de dispensa para êsse casamento, devido à consangüinidade (34) .

De acôrdo com os dados de Pedro Taques, as demarches para o casamento teriam então levado vários anos, pois a petição de dispensa era de 1710 e o casamento se teria realizado em 1714 .

Temos a impressão de que há um engano do linhagista: a petição de dispensa foi deferida a $1^{\text {90 }}$ de junho de 1710 (35). Não have-

(29). - Pedro Taques, ob. cit., pág. 152. Costumavam os paulistas penetrar cs vantíssimos sertôes do Rio Paraguai, chegando ao Peru, às minas de Potosí, de cuja prata se aproveitavam e de que "enobreceram suas casas com copa de muitas alrôbas". (Cf. Pedro Taques, ob. cit., I, pág. 115).

(30). - Pedro Taques, ob. cit., I, pág. 152.

(31). - Idem, pág. 155.

(32): - Na época de seu casamento contava oitenta mil cruzados em escravos e sítios rendosos nas minas, além de "algum dinheiro que tem em Lisboa". (Inventários e Testamentos, vol. 27, pág. 168.

(33). - Pedro Taques, ob. cit., I, pág. 153.

(34). - Em uma petição apresentada a 4 de abril de 1710 no Rio de Janeiro ao vigário da vara, a dispensa para o casamento é solicitada em nome de José de Góes e Moraes e Ana Ribairo de Almeida (Inventários e Testamentos, vol. 27, pág. 167). Também Azevedo Marques (ob. cit., II, pág. 58), quando se refere à espôsa de José de Góes, cita o sobrenome Almeida e não Leite.

(35). - Inventários e Testamentos, vol. 27, pág. 179. 
ria razão de pêso para que 0 casamento levasse ainda 4 anos para se realizar.

A união contribuiu para fortalecer o patrimônio de José de Góis, pois Ana Ribeiro levava um dote de vinte mil cruzados,

\author{
"computando-se nesta quantia alguma prata lavrada e ouro \\ de seu uso" (36).
}

Com famí ia constituída e fortuna assegurada, passa a atuar com frequiência no cenário político da Capitania. Por carta régia de 14 de março de 1711 tornou-se capitão-mór da vila de São Paulo (37) que, a 24 de julho dêsse ano era elevada à categoria de cidade (38).

No dia 4 de janeiro de 1715 , tendo sido eleito juiz ordinário da cidade de São Paulo, prestava juramento na casa da Câmara (39). Como presidente nato, cabia-lhe dirigir as sessões da Câmara, composta ainda de outros oficiais, entre os quais, além dos vereadores, um escrivão, um procurador e mais um tesoureiro (40).

A eleição de José de Góis é prova de seu prestígio e de sua "nobreza", pois não podiam ser eleitos membros das ICâmaras,

"pessoas mecânicas, mercadores, filhos do reino, gente de nação (judeus), soldados nem degredados e sim nobres sòmente, naturais da terra e descendentes dos conquistadores e povoadores; segundo diversos alvarás e cartas régias que vão de 1643 a 1747", (41).

E' verdade que em São Paulo, sempre falto de gente e parco de condições econômicas, essa aristocratização nem sempre era rígida. A eleição de mecânicos, alfaiates, mostra que, vez por outra, a lei deixava de ser seguida...

Todavia, a exclusão de "filhos do reino" das Câmaras, evidencia o zêlo destas, no tocante às prerrogativas de que dispunham. Ciosas de suas conquistas, tornaram-se num certo momento,

"a principal autoridade das Capitanias respectivas, sobrepondo-se aos próprios governadores e chegando até a destitui-los do seu pôsto" (42).

(36). - Inventários e Testamentos, vol. 27, pág. 168.

(37). - Pedro Taques, ob. cit., I, pág. 152.

(38). - Machado de Oliveira, ob. cit., pág. 126.

(39). - Atas da Câmara de São Paulo, vol. 8, pág. 527.

(40). - Cf. Garcia (Rodolfo), Ensaio sôbre a história politica e administrativa do Brasil (1500-1810). Rio de Janeiro, 1956, pág. 97.

(41). - Ibidem, pág. 103.

(42). - Prado Jr. (Caio), Formação do Brasil Contemporâneo, São Paulo, 1957, pág. 314. 
No exercício de sua função naquele ano, tratou José de Góis de problemas vários como o da correição geral solicitada a 29 de janeiro (43) ou a feitura de uma ponte sôbre o rio Tietê, na estrada da Conceição, a cargo dos moradores (44).

Em 1717 encontrâmo-lo como arrematador dos subsídios (45). $\mathrm{O}$ arrendamento dos subsídios relativos aos três líquidos principais - vinho, aguardente e azeite - representava o principal recurso auferido pela Câmara;

“a não ser isto, algumas dezenas de mil réis, quiçá uma centena e meia ou duas lhe vinham da cobrança de multas e das licenças de vendagem, as avenças" (46).

Por essa época, a renda da cidade de São Paulo girava em tôrno de quinhentos mil réis, dos quais trezentos, aproximadamente, corresponderiam aos subsídios.

Ora, quinhentos mil réis eqüivaliam a 1.250 cruzados. Por aí, pode-se avaliar o cabedal de que dispunha José de Góis, pois oferecendo 44 mil cruzados ao donatário da Capitania de São Vicente, estabelecia o eqüivalente a 40 vêzes aproximadamente a renda da cidade onde nascera.

Em troca da arrematação dos subsídios por três anos, propunha-se a construir em igual prazo nova Casa do Conselho e cadeia pública

$$
\text { "pela emcapacidade de hua e outra morada" (47). }
$$

Para isso, apresentava planta a ser aprovada pelos componentes do Conselho. O ajuste foi feito. Teria sido concluído? Em junho de 1718 há uma referência da Câmara

"para effeito de obrigarem ao Capitam Mor Jozeph de Goes e Moraes a que pegue na obra da cadea e caza do conss.o e a faça dentro de dous annos que lhe restão..." (48).

Enquanto a cidadezinha de São Paulo prosseguia nas suas modestas ocupações e no seu parco viver, sucediam-se os descobrimentos auríferos fora do território paulistano. Descobriram-se as minas de

(43). - Atas da Câmara de São Paulo, vol. 8, pág. 329.

(44). - Ibidem, pág. 330. O juiz ordinário, além de suas funções como membro do Senado e seu presidente, tinha uma esfera própria que, sôbre ser judiciário, era também administrativa. Cabia-lhe julgar e proferir sentenças, resolver litígios e executar ainda as providências da administıação.

(45). - Ibidem, págs. 383-384.

(46). - Taunay, História da cidade de São Paulo no século XVIII (17211734), 2.0 tomo, in "Anais do Museu Paulista", tomo VI, São Paulo, 1933.

(47). - Atas da Câmara, vol. 8, págs. 383-384.

(48). - Ibidcm, pág. 483. 
Paranapanema. A essa altura, São Paulo já não mais formava com o Rio de Janeiro uma só capitania (49).

Com o desmembramento, as terras descobertas pelos paulistas ao norte, foram incorporadas às Capitanias que levavam o nome de São Vicente e Santo Amaro - o vastíssimo território assim formado passou a receber o nome de Capitania de São Paulo e Minas do Ouro, tendo como capital a cidade de São Paulo.

$\mathrm{Na}$ ocasião em que as minas de Paranapanema foram descobertas, governava a Capitania D. Pedro de Almeida, conde de Assumar, o qual, nesse ano de 1718, atribuiu a José de Góis e Morais o cargo de guarda-mór das ditas minas (50). Ao detentor dêste cargo estabeecido pelo Regimento das Minas de 1702 , cabia a repartição das terras auríferas $(51)$.

O cargo deveria conceder prestígio e ser rendoso, pois afora o salário que lhe era devido, havia a perspectiva de maiores oportunidades para a aquisição de terras preciosas em minério de ouro.

Se José de Góis precisou ausentar-se de São Paulo para atender a tal mistér, sua ausência foi de curta duração, pois nas atas da Câmara de 1719 há diversas referências à sua pessoa como presente na cidade (52).

Em 1737 voltaria a ser juiz ordinário, por eleição estabelecida

"ao primeiro dia do mês de dezembro de mil setecentos e trinta e seis annos nesta cidade de sam paulo em as cazas do senado da camara" (53).

Até essa época, o prestígio das corporações municipais era inconteste e as suas prerrogativas, como já foi mencionado, exorbitavam muitas vêzes das atribuições que lhes davam as leis.

Orgulhosos por fôtça da nobreza de seus ascendentes, animados pelo espírito de liberdade que caracteriza a gente americana, passan-

(49). - A separação deu-se a 9 de novembro de 1709. Posteriormente São Paulo foi agregada novamente ao Rio de Janeiro e só com a vinda do Morgado de Mateus em 1765, desligou-se definitivamente, prosseguindo como Capitania autônoma.

50). - Pedro Taques, Notícias das minas de São Paulo $e$ dos sertões da mesma Capitania, São Paulo, 1954, pág. 88.

(51). - Maiores referências à ação do guarda-mor são encontradas em Holanda (Sérgio Buarque de), Metais e pedras preciosas, in "História Geral da Civilização Brasileira", livro IV, vol. 2, pág. 270.

(52). - Sessão de 25-1-1719, determinando que José de Góes efetuasse pagamento de 25\$000 (Atas da Câmara, vol. 8, p. 471).

Sessão de 18-2-1719, mandado para que José de Góes ordenasse a construção de "dois tabocens para hum tronco"( ( ) (Atas, vol. 8, p. 472.

Sessão de 1-5-1719, mandado para que José de Góes pagasse $100 \$ 000$ dos subsídios referentes à obrigação assumida (Atas, vol. 8, p. 477).

(53). - Atas da Câmara, vol. 8, p. 494. 
do grande parte da vida nos sertões, longe de tôda a vigilância, nunca foram os. paulistas submissos, acentuando a sua independência sob a dominaçẫo espanhola (54). Originavam-se dessa forma freqüentes conflitos, por vêzes sangrentos, entre as Câmaras, governadores e outras autoridades (55) e que levaram um governador a escrever a El-Rei,' tachando de "terras pouco obedientes" as de São Paulo e São Vicente (56) .

Paulatinamente os podêres gerais forçaram as Câmaras a circunscrever-se na órbita das atribuições determinadas pelas Ordenações do Reino, chegando-se a conseguir isso no decorrer do século XVIII.

São Paulo não escaparia a essa situação, embora revoltando-se contra a intromissão sempre crescente dos reinóis na governança municipal.

Assim, José de Góis não exerceria o seu cargo de juiz ordinário. Nos fins de 1736 irrompia em São Paulo séria crise política derivada do espírito nativista, que se rebelava contra as prerrogativas cada vez maiores dos portuguêses, considerados como invasores.

João Rodrigues Campello, o ouvidor-geral da Comarca nessa ocasião, protegia os reinóis. Feita a e’eição em que José de Góis se sagrou juiz ordinário, o partido português impugnou-a e obteve que se procedesse a nova eleição, na qual os paulistas votaram em branco.

Os reinóis conseguiram que o ouvidor-geral thes desse ganho de causa e, apesar do enérgico protesto lavrado por Pedro Taques Pires em nome dos brios locais, a Câmara ilegal foi empossada a 1-1-1737 (57):

\footnotetext{
"estava desrespeitado e vencido o princípio já quase secular que presidia à formação da municipalidade paulistana. O prestígio de seus cargos, dizem os cronistas, cairia cada vez mais pelo século XVIII afora. À medida que avança o século XVIII, acentua-se em todo o Brasil o absolutismo dos capitães-generais, nulificando o pequeno papel das corporaçōes municipais" (58).
}

Mesmo assim, com a sobranceria que os caracterizava, lutavam os de São Paulo por todos os meios e em tôdas as ocasiões, para salvaguardar a sua independência ou para ao menos mostrar que não recebiam golpes passivamente.

(54). - Saint-Hilaire (Auguste), Segunda Viagem a São Paulo e Quadro Histórico da Província de São Paulo, São Paulo, 1954, p. 158.

(55). - Rodolfo Garcia, ob. cit., p. 96.

(56). - Câmara Coutinho, que se insurgia contra as insolências dos paulistas que corriam o sertão (Apud Holanda, Sérgio Buarque, Metais... p. 262).

(57). - Cf. Taunay, ob. cit., (1721-1734); $3^{\circ}$ tomo, p. 52.

(58). - Ibidem, p. 67-68. 
Ainda nesse ano de 1737 foi recebido em São Paulo com as homenagens devidas ao cargo o governador interino da Capitania, Gomes Freire de Andrade (59).

Como os demais governadores, não residia em São Paulo, o que muito aborrecia os paulistas pelo que consideravam uma capitis diminutio (60).

A Câmara teve o seu revide quando, dois anos depois, chegava a São Paulo o nôvo capitão-general, D. Luís de Marcarenhas, governador da Capitania e representante d'El-Rei D. João V, que aqui vinha se fixar.

Foi questão de honra festejar a chegada com estrondosas cerimônias e homenagens muito mais pomposas que aquelas recebidas por Gomes Freire. Nessa ocasião entre os notáveis da terra a segurar o pálio que protegeria o general figurava o capitão-mór José de Góis (61).

Embora Pedro Taques afirme ter sido êle duas vêzes eleito juiz ordinário, encontrâmo-lo numa terceira ocasião escolhido para tal cargo, em 1741 (62).

Muitos anos depois, já velho e cansado, o bravo paulista ainda uma vez seria distinguido com a nomeação para uma função pública: no final de 1759 procedeu-se à

"eleição para fiscal da Real Casa da Fundição desta cidade e saiu eleito por maioria de votos o capitão-mor José de Góes e Morais em quem concorrem os requisitos necessários para entrar a servir o seu trimestre que há de principiar a 14 de fevereiro de 1760 e há de findar a 14 de maio do mesmo ano" (63).

Mas aos 89 anos de idade, não mais teria condições de servir à sua terra. Por velho e doente, desistiu do cargo (64).

Morreria aos 92 anos,

"acabando a vida no de 1763 , a 20 de agôsto, com testamento no qual com humildade pediu que sem pompa funeral fôsse sepultado na capela da Ordem Terceira de Nossa Senhora do Carmo, onde, irmão professo, tinha jazigo próprio, em que descansam suas cinzas" (65).

(59). - Já era governador do Rio de Janeiro désde 1733.

(60). - Os governadores da Capitania de São Paulo e Minas do Ouro só vinham a São Paulo para tomar posse, indo residir em Mariana.

(61). - Cf. Taunay, ob. cit., 1721-1734, $3^{\circ}$ tomo, p. 174.

(62). - Atas da Câmara de São Paulo, vol. 11, p. 321.

(63). - Ibidem, vol. 14, p. 268.

(64) . - "Têrmo de desistência que faz o capitão-mór José de’'Góes e Moraes da ocupação de fiscal em que foi eleito", in Atas da Câmara, vol. 14, p. 283.

(65). - Pcdro Taques, Nobiliarquia..., I, p. 153. 
Na história de uma São Paulo setecentista, a figura de José de Góis e Moraes sobressai curiosa como a do indivíduo ousado, que não hesita em atirar-se a tipos de negócio, em geral só empreendidos pelos podêres públicos.

E' uma figura digna de seu tempo, de um tempo em que o arrôjo, a valentia, certa dose de aventureirismo eram condições básicas para se sobreviver em terra que, apesar de sua fertilidade, vegetava na pobreza, forçando os fi'hos a irem buscar no sertão os meios de comércio de que necessitavam.

A Capitania de São Vicente com suas terras litorâneas apertadas entre o mar e a montanha, tendo o grande planalto interior separado dos portos de embarque pela Serra do Mar, enfrentava dificuldades para se integrar em uma economia de exportação.

Seus habitantes encontraram na preação de índios um comércio rendoso. Descobertas as minas, acorrem a elas pressurosos, quase despovoando a terra natal.

José de Góis foi um dêsses bravos paulistas que participaram do movimento minerador, internando-se no sertão sombrio que exigia a rijeza e tenacidade só concedida aos homens fortes. Dedicar-se-ia ao rendoso comércio de gado para alimentar os que extraíam o precioso metal mas não se fixaria na região mineira como tantos outros paulistas o fizeram. Voltaria fielmente para o lugar onde nascera, com o grande cabedal que o faria, segundo os cronistas, um dos homens mais ricos de seu tempo.

Não era seguramente um Creso, mas teria superado largamente em bens o seu parente Padre Pompeu, que os exageros de Pedro Taques levaram a aureolar-se com a fama de homem mais rico da Capitania (66).

Seria a opulência de José de Góis realmente notável? Com certe$\mathrm{za}$, para os padrões da época. Algumas poucas fortunas individuais contrastariam o suficiente com a pobreza da Capitania para que os contemporâneos as exaltassem e talvez até, as superestimassem.

(66). - Em 1710, José de Góes além de 80 mil cruzados em sítios e escravos, possuía "algum dinheiro" em Lisboa que correspondia a 60 mil cruzados, segundo o Pe. Lourenço de Toledo Taques (Inventários e Testamentos, vol. 27, p. 173). Era realmente uma fortuna considerável, pois o famoso Padre Pompeu teria à época em que faleceu, 1713, sessenta mil cruzados, o que o deixa em acentuada inferioridade em relação a José de Góes (Cf. Cahn Herbert), Padre Guilherme Pompeu de Almeida e suas atividades comerciais (1686-1713) - Tese de doutoramento apresentada à Cadeira de História da Civilização Brasileira da Faculdade de Filosofia, Ciências e Letras da Universidade de São Paulo, em 1967. 
E' de se notar que a idéia de luxo cingia-se a poucos aspectos da vida material, embora pareça certo pelas descrições de Pedro Taques que José de Góis requintava em um viver pouco usual entre seus conterrâneos.

Houvesse êle consumado a compra da Capitania, teria em alguma coisa modificado o curso de sua história? Temerário responder.

Nem por isso, deixou de projetar-se no cenário político paulistano como um dos "homens bons" de sua cidade.

A frieza das fontes não permite esboçar-lhe a personalidade inteira. Era altamente respeitado - certamente isso se pode afirmar; são constantes as citações de documentos em que aparece como fiador da respeitabilidade de outros contemporâneos.

Dedicando-se embora à causa pública, nunca deixou de ocupar-se de seus negócios particulares. Há numerosos documentos que abrangem os anos de 1718 a 1753 , em que José de Góis aparece movendo ações a indivíduos que lhe devem quantias, por vêzes avultadas (67).

Do seu modo de ser, temos de louvar-nos no que dizem os cronistas:

"foi dotado de claro juízo, grande compreensão e discrição", tendo ainda "natural docilidade a que soube unir a urbanidade, sem diminuição do respeito que sempre gozou..." (68). .

Gozando em vida dos requintes materiais que a sua abastança lhe permitia, seria na morte, fiel às espartanas tradições de seu tempo e de sua terra, pois por vontade expressa foi enterrado

"sem campa nem epitáfio que aos fiéis lembre o nome dêste cavalheiro que na pátria soube conservar com aplausos e geral obséquio todo o louvor" (69).

(67). - E' o caso por exemplo do documento 2927 que transcreve um libelo de José de Góes contra Joanna Baptista, exigindo pagamento da quantia de duzentos mil réis que lhe ficara a dever o marido da suplicada e pela qual deveria ser ela responsável, em razão de ter êle "falecido da vida prez.te" (Autos cíveiss, Tempo colonial, Arquivo do Estado de São Paulo, cx. 104).

Outros dêsse teor são encontrados nos mesmos Autos Cíveis, cx. 4, 11, 22, 27, $30,33,34,39,62,64,68,80,101,142$.

(68). - Pedro Taques, Nobiliarquia..., I, p. 153.

(69). - Ibidem. 